\title{
Marine water quality assessment and comparison during major and minor tides in near sea area of Fujian Province
}

\author{
Yang $\mathrm{LuO}^{1}$, Wanmin $\mathrm{Ni}^{2}$, Ling $\mathrm{Cai}^{1}$, Haining Huang ${ }^{1}$, Liping Jiao ${ }^{1, *}$ \\ ${ }^{1}$ Third Institute of Oceanography, State Oceanic Administration, Xiamen, China \\ ${ }^{2}$ Zhejiang International Studies University, Hangzhou, China
}

Keywords: Water Quality Survey, Ecological Assessment, Near-shore, Eutrophication.

\begin{abstract}
In order to evaluate the potential ecological risks of near shore area of Fujian Province, four surveys on marine water quality at 20 monitoring sites were carried out during the major and minor tides in the autumn of 2010 and the spring of 2012. The results showed that the background values of heavy metals in the waters were generally low, but eutrophication was obvious. Eutrophication in the autumn was more severe than in the spring. The indices of inorganic nitrogen and active phosphate at all monitoring sites in autumn exceeded the quality standard for sea water.
\end{abstract}

\section{Introduction}

In the past decades, China's accelerating industrialization and rapid economic development have brought about a series of environmental problems. Because of the development of coastal industry, excessive emissions of heavy metal and toxic organic substances pouring into the sea pose great threats to the stability of ecosystem and human health (Pan and Wang, 2012). Sediments function as the source and sink of environmental pollutants with a high susceptibility to environmental changes. Therefore, sediments can be used as the evaluation indicator for potential ecological risks (Adams et al. 1992; Pikey, 2006; Wu et al., 2006). The heavy metals in the aquatic ecosystem have an especially high toxicity and exist in the environment persistently. The heavy metals accumulating in the aquatic creatures, threatens the human health by the effect of biological magnification via the food chain. Therefore, heavy metals have become the common evaluation indicators for marine ecological risks (Sundry et al., 2011; Tessie et al., 2011; Varo, 2011).

Most of the existing reports on the near shore pollution in China are concerned with Bhai Bay (Feng et al., 2011; GAO and Chen, 2012; GAO and Li, 2012) and East China Sea (Liu et al., 2011; Gao, 1998). The researches about near shore areas of Fujian Province focus on the survey of seawater quality (Awing, 2000; Chen and Cheng, 2001) and the distribution of heavy metals in the sediments (Awing et al., 2002; Luo et al., 2004; Zhang et al., 2013). However, the marine biodiversity and the ecological environment quality are rarely reported (Yang, 2012). This article addresses the problem of potential ecological risks of near shore areas in Fujian Province. Four surveys on water quality at 20 monitoring sites were carried out during the major and minor tides in the autumn of 2010 and the spring of 2012. The purpose was to provide basic data for ecological conservation and sustainable development of ecosystem for near shore area of Fujian Province.

Overview of the research area. Sangria Harbor is located on the northeast bank outside Fusing Bay, with its rear adjacent to Sangria Town and Yuan Hong Development Zone. The distance from Fuzhou City is about 55 to 70 km. In 1994, 30-thousand-ton Yuan Hong Harbor was built under foreign funding. The passing capacity is 1 million ton. Hong Yuan Harbor is mainly responsible for supplying supporting services to Yuan Hong Flour Mill in the rear and other food industry. The length of coastline from Komen on the north bank of Fusing Bay to the south segment of Liangcuo Town is $2100 \mathrm{~m}$. This segment of coastline is located near Guyu Island, Jidiao Island and Yutou Island, and adjacent to tidal inlet. The water depth is 5 to $15 \mathrm{~m}$, and the total length of harbor coastline is $2160 \mathrm{~m}$. ten Deepwater berths can be accommodated in the harbor, and the passing capacity is about 10 million ton. Changle Sea Clam Resources Protection Zone is a marine nature reservoir. It extends from Lizhuang of Meihua Town in the north to Yunmujiao of Jiangtian Town in the south, 
running along the coastline of Changle in the west and reaching $10 \mathrm{~m}$ bathymetric contour in the east. The total area of the Protection Zone is 12,999 hectares. Xiasha Coastal Tourism Resort is located in Xiasha Beach of Changle City, covering an area of about $441.3 \mathrm{~km} 2$ with the central position at $25^{\circ} 47^{\prime} 22^{\prime \prime} \mathrm{N}, 119^{\circ} 36^{\prime} 47^{\prime \prime} \mathrm{E}$. This region has beautiful beach, and is currently utilized as the bathing beach. According to Marine Functional Zoning of Fujian Province (2011-2020), Dongluo Archipelago Resort will be built in the sea area to the east of Changle City, covering an area of about $1202 \mathrm{~km}^{2}$ with the central position at $25^{\circ} 46^{\prime} 00^{\prime \prime} \mathrm{N}, 119^{\circ} 40^{\prime} 36^{\prime \prime} \mathrm{E}$. The quality standard for seawater not lower than class II is implemented in this area.

Water quality survey and ecological environment evaluation were carried out during the major and minor tides in the spring and autumn in near shore area of Fujian Province. A total of 20 monitoring sites were arranged. Sites S1-S4, S6 and S7 were located in Xiasha-Dongluo Resort and Environmental Protection Zone. The class II quality standard for sea water is implemented in the short- and long-term. Sites S5, S8, S9, S11, S12, S14, S15, S17 and S19 are located in Songxia-Chengtou Harbor and the industrial development supervision zone (Fig. 1). The class III quality standard for sea water is implemented in the short- and long-term. Other sites are located in the ecological corridors in the north of Haitian Strait. Class II quality standard for sea water is implemented in the short- and long-term.

Research methods. Four samplings were done during the major and minor tides in the autumn of 2010 and the spring of 2012. The positions of the 20 sites and the monitoring indicators are shown in Table 1.

Water quality indicators included: water temperature, salinity, $\mathrm{pH}$, dissolved oxygen, chemical oxygen demand, nitrate, nitrite, ammonium, phosphate, total suspended matter, petroleum hydrocarbons, sulfides, volatile phenols, copper, lead, zinc, cadmium, chromium, mercury, arsenic. The layers sampled were surface layer $(<5 \mathrm{~m})$, middle layer $(\geq 5 \mathrm{~m},<10 \mathrm{~m})$, bottom layer $(\geq 10 \mathrm{~m}) .10$ indicators were determined: petroleum hydrocarbons, sulphides, volatile phenols, copper, zinc, lead, cadmium, chromium, mercury and arsenic. Only the surface layer was sampled. Sample collection, preservation and analysis were done in accordance with GB17378.3 and GB17378.4 of The Specification for Marine Monitoring.

Single factor index method (Hakanson L, 1980) was adopted to evaluate the current situation of water quality. When air pollution index (Pi) was larger than 1 , it was considered that the water quality standard was exceeded. The formula for the calculation of Pi for each indicator is as follows:

$\mathrm{Pi}$ for all pollutants except $\mathrm{pH}$ and $\mathrm{DO}$ is given by $\mathrm{Pi}=\mathrm{Ci} / \mathrm{Csi}$, where $\mathrm{Pi}$ is single-factor $\mathrm{Pi}$; $\mathrm{Ci}$ is the monitored value; Csi is the standard value.

$\mathrm{Pi}$ for $\mathrm{pH}$ is given by

$\mathrm{PIpH}=\frac{\left|p H-p H_{s m}\right|}{D_{s}}$, where $\mathrm{pHsm}=\frac{p H_{s u}+p H_{s d}}{2}, \mathrm{DS}=\frac{p H_{s u}-p H_{s d}}{2}$.

Where PIpH is the Pi of ph.

$\mathrm{PH}$ is the monitored value of $\mathrm{ph}$.

PHsu is the upper bound specified by the evaluation standard.

PHsd is the lower bound specified by the evaluation standard.

$\mathrm{Pi}$ for DO is given by

$$
P I_{D O}=\frac{\left|D O_{f}-D O_{i}\right|}{D O_{f}-D O_{s}}\left(D O_{i} \geq D O_{s}\right), \quad P_{i}=10-9 \times \frac{D O_{i}}{D O_{s}}\left(D O_{i}<D O_{s}\right), \quad D O_{f}=\frac{468}{31.6+T}
$$

Where PIDO is the Pi of DO at site I; DOf is DO saturation concentration; T is water temperature $\left({ }^{\circ} \mathrm{C}\right)$; DOi is DO concentration at point I; DOs is the evaluation standard for DO.

\section{Results and discussion}

Data in table 2 and table 3 showed that the water temperature at each near shore survey site in the two voyages in the spring was $19.0-20.65^{\circ} \mathrm{C}$, and that in autumn was $18.0-20.8{ }^{\circ} \mathrm{C}$. The measured value of salinity in the two voyages in spring was $21.44-27.04$, and in autumn was $26.75-28.86$. The sea area in the east of Change is greatly influenced by continental runoff, and hence the salinity is low. The 
measured value of $\mathrm{pH}$ in the two voyages in spring was 7.90-8.31, and Pi was 0.03-0.72. The measured value of $\mathrm{pH}$ in the two voyages in November of 2010 was 8.12-8.38, and Pi was 0.03-0.57. The values measured in all four voyages met the corresponding quality standards for sea water. They all satisfied the class I quality standard for sea water.

The contents of suspended sediment particles measured in the four voyages in spring and autumn were $2.5 \mathrm{mg} \cdot \mathrm{L}^{-1}-60.0 \mathrm{mg} \cdot \mathrm{L}^{-1}$, and the difference between different sites is significant. The measured values of DO in the two voyages in spring were $7.67 \mathrm{mg} \bullet \mathrm{L}^{-1}-11.38 \mathrm{mg} \cdot \mathrm{L}^{-1}$, and Pi values were 0.01-0.48, which satisfied the corresponding quality standards for sea water. The measured values of DO in the two voyages in autumn were $6.86 \mathrm{mg} \bullet \mathrm{L}^{-1}-7.96 \mathrm{mg} \bullet \mathrm{L}^{-1}$, and Pi values were $0.34-0.60$. They also satisfied the corresponding quality standards for sea water. The measured values of Cod MN in the two voyages in spring were $0.70 \mathrm{mg} \cdot \mathrm{L}^{-1}-2.59 \mathrm{mg} \cdot \mathrm{L}^{-1}$, and Pi values were $0.18-0.58$. The measured values of COD MN in the two voyages in autumn were $0.42 \mathrm{mg} \cdot \mathrm{L}^{-1}-1.08 \mathrm{mg} \cdot \mathrm{L}^{-1}$, the average $0.65 \mathrm{mg} \bullet \mathrm{L}^{-1}$, and the Pi value $0.12-0.27$. They satisfied not only the corresponding quality standards, but also the class I quality standard for sea water.

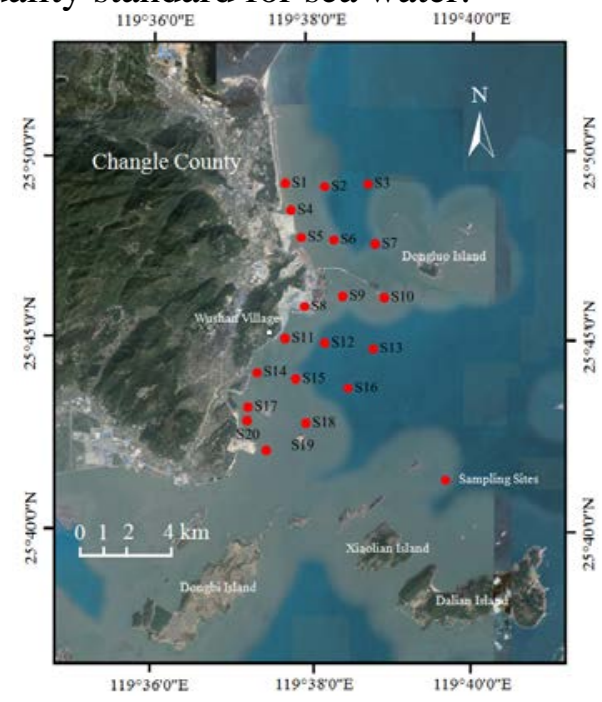

Fig.1 Sampling sites

Table 1 Locations and monitoring parameters for all sampling sites

\begin{tabular}{|c|c|c|c|c|c|c|}
\hline te & & & & 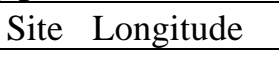 & & \\
\hline S1 & $\begin{array}{c}119^{\circ} 36^{\prime} \\
"\end{array}$ & 2 & Iality & $1^{119^{\circ} 36^{\prime}}$ & & $\mathrm{Cl}_{1}$ \\
\hline S2 & $\begin{array}{c}119^{\circ} 37^{\prime} 5 \\
"\end{array}$ & $\begin{array}{c}25^{\circ} 47^{\prime} 2 \\
"\end{array}$ & e & $\begin{array}{l}\circ 37 ! \\
"\end{array}$ & ○ & $\begin{array}{r}\text { ter qua } \\
\mathrm{C}\end{array}$ \\
\hline S3 & $\begin{array}{c}119^{\circ} 38^{\prime} 53.03 \\
"\end{array}$ & $\begin{array}{c}25^{\circ} 47^{\prime} 30 .( \\
"\end{array}$ & & 3 & 2 & ' Water quality, Sedimer \\
\hline S4 & $119^{\circ} 37^{\prime} 6$. & $\begin{array}{c}25^{\circ} 46^{\prime} 5 \\
"\end{array}$ & & $14^{119^{\circ} 36^{\prime} 1}$ & 2 & \\
\hline S5 & $\begin{array}{c}119^{\circ} 37^{\prime} 20.2 \\
"\end{array}$ & $\begin{array}{c}25^{\circ} 46^{\prime} 23.65 \\
"\end{array}$ & C & $15^{119^{\circ} 37^{\prime} 1}$ & $\begin{array}{l}{ }^{\circ} 43^{\prime} \\
\text { " }\end{array}$ & Water qua \\
\hline S6 & $119^{\circ} 38^{\prime} 5$. & $\begin{array}{c}25^{\circ} 46^{\prime} 20.52 \\
"\end{array}$ & Water qu & $\begin{array}{c}38 \text { '2 } \\
"\end{array}$ & 13 & Water s \\
\hline S7 & 9³9'3.00" & $\begin{array}{c}25^{\circ} 46^{\prime} 15.44 \\
"\end{array}$ & & ॰36'6.67" & $\begin{array}{c}25^{\circ} 42^{\prime} 5 \\
n\end{array}$ & $\mathrm{Cl}$ \\
\hline S8 & $\begin{array}{c}119^{\circ} 37^{\prime} 25.15 \\
"\end{array}$ & $\begin{array}{c}25^{\circ} 44^{\prime} 57.53 \\
"\end{array}$ & Water qu & $\mathrm{S} 18^{119^{\circ} 37^{\prime} 2}$ & $25^{\circ} 42^{\prime}$ & IT \\
\hline S9 & $\begin{array}{c}19^{\circ} 38^{\prime} 18.08 \\
"\end{array}$ & $\begin{array}{c}25^{\circ} 45^{\prime} 10.62 \\
"\end{array}$ & & 44" & $25^{\circ} 42$ & vracer quanty, seum \\
\hline & $\begin{array}{c}119^{\circ} 39^{\prime} 15.3 \\
\end{array}$ & $25^{\circ} 45^{\prime} 8.75$ & ter quality, $\varsigma$ & $\mathrm{S} 20^{1}$ & $\begin{array}{c}\circ 41 ' 58.2 \\
\text { " }\end{array}$ & Water que \\
\hline
\end{tabular}


Table 2 Pi index for water quality investigation of 20 sampling sites in autumn, 2010

\begin{tabular}{|c|c|c|c|c|c|c|c|c|c|c|c|c|c|c|}
\hline \multicolumn{8}{|c|}{ Major tides } & \multicolumn{7}{|c|}{ Minor tides } \\
\hline Site & $\mathrm{pH}$ & DO & $\mathrm{COD}_{\mathrm{Mn}}$ & DIN & $\mathrm{PO}_{4}{ }^{3-}-\mathrm{P}$ & $\mathrm{PH}$ & Sul. & $\mathrm{pH}$ & $\mathrm{DO}$ & $\mathrm{COD}_{\mathrm{Mn}}$ & DIN & $\mathrm{PO}_{4}^{3-}-\mathrm{P}$ & $\mathrm{PH}$ & Sul. \\
\hline \multirow{2}{*}{ S1 } & 0.2 & 0.3 & & & 1.20 & 0.4 & 0.0 & 0.0 & 0.4 & & & 1.20 & 0.3 & 0.0 \\
\hline & 3 & 4 & 0.20 & 2.63 & & 3 & 3 & 9 & 1 & 0.21 & 2.27 & & 1 & 1 \\
\hline \multirow{2}{*}{ S2 } & 0.2 & 0.3 & & & 1.30 & 0.4 & 0.0 & 0.1 & 0.4 & & & 1.13 & 0.2 & 0.0 \\
\hline & 3 & 6 & 0.17 & 2.53 & & 9 & 3 & 4 & 5 & 0.17 & 2.17 & & 7 & 1 \\
\hline \multirow{2}{*}{ S3 } & 0.2 & 0.3 & & & 1.30 & 0.6 & 0.0 & 0.1 & 0.4 & & & 1.20 & 0.2 & 0.0 \\
\hline & 3 & 5 & 0.15 & 2.43 & & 3 & 4 & 4 & 3 & 0.21 & 2.10 & & 0 & 1 \\
\hline \multirow{2}{*}{ S4 } & 0.2 & 0.3 & & & 1.57 & 0.5 & 0.0 & 0.1 & 0.4 & & & 1.27 & 0.3 & 0.0 \\
\hline & 6 & 5 & 0.26 & 2.57 & & 6 & 4 & 4 & 4 & 0.24 & 2.47 & & 5 & 1 \\
\hline \multirow{2}{*}{ S5 } & 0.4 & 0.3 & & & 1.47 & 0.1 & 0.0 & 0.3 & 0.4 & & & 1.20 & 0.0 & 0.0 \\
\hline & 3 & 7 & 0.19 & 2.10 & & 0 & 2 & 9 & 4 & 0.15 & 1.70 & & 5 & 0 \\
\hline \multirow{2}{*}{ S6 } & 0.2 & 0.3 & & & 1.27 & 0.4 & 0.0 & 0.0 & 0.4 & & & 1.13 & 0.2 & 0.0 \\
\hline & 6 & 5 & 0.14 & 2.47 & & 6 & 3 & 9 & 2 & 0.24 & 2.10 & & 9 & 1 \\
\hline \multirow{2}{*}{ S7 } & 0.2 & 0.3 & & & 1.27 & 0.2 & 0.0 & 0.1 & 0.4 & & & 1.20 & 0.2 & 0.0 \\
\hline & 3 & 7 & 0.17 & 2.43 & & 0 & 4 & 4 & 4 & 0.23 & 2.00 & & 3 & 1 \\
\hline \multirow{2}{*}{ S8 } & 0.4 & 0.3 & & & 1.30 & 0.0 & 0.0 & 0.3 & 0.4 & & & 1.20 & 0.0 & 0.0 \\
\hline & 3 & 9 & 0.14 & 1.75 & & 6 & 1 & 7 & 4 & 0.11 & 1.65 & & 4 & 2 \\
\hline \multirow{2}{*}{ S9 } & 0.4 & 0.4 & & & 1.30 & 0.0 & 0.0 & 0.3 & 0.4 & & & 1.17 & 0.0 & 0.0 \\
\hline & 4 & 4 & 0.15 & 1.75 & & 9 & 2 & 8 & 3 & 0.15 & 1.63 & & 6 & 2 \\
\hline \multirow{2}{*}{ S10 } & 0.2 & 0.3 & & & 1.23 & 0.6 & 0.0 & 0.1 & 0.4 & & & 1.20 & 0.2 & 0.0 \\
\hline & 6 & 9 & 0.20 & 2.37 & & 1 & 2 & 4 & 5 & 0.25 & 2.40 & & 5 & 1 \\
\hline \multirow{2}{*}{ S11 } & 0.4 & 0.3 & & & 1.27 & 0.0 & 0.0 & 0.3 & 0.4 & & & 1.30 & 0.0 & 0.0 \\
\hline & 3 & 8 & 0.15 & 1.78 & & 6 & 2 & 8 & 5 & 0.15 & 1.73 & & 4 & 1 \\
\hline \multirow{2}{*}{ S12 } & 0.4 & 0.3 & & & 1.30 & 0.0 & 0.0 & 0.3 & 0.4 & & & 1.23 & 0.0 & 0.0 \\
\hline & 4 & 8 & 0.23 & 1.85 & & 5 & 3 & 8 & 6 & 0.19 & 1.70 & & 5 & 0 \\
\hline \multirow{2}{*}{ S13 } & 0.0 & 0.4 & & & 1.27 & 0.4 & 0.0 & 0.1 & 0.4 & & & 1.20 & 0.2 & 0.0 \\
\hline & 6 & 0 & 0.18 & 2.37 & & 1 & 3 & 1 & 5 & 0.27 & 2.13 & & 2 & 1 \\
\hline \multirow{2}{*}{ S14 } & 0.4 & 0.3 & & & 1.27 & 0.0 & 0.0 & 0.3 & 0.4 & & & 1.37 & 0.0 & 0.0 \\
\hline & 3 & 7 & 0.18 & 1.73 & & 5 & 1 & 9 & 5 & 0.18 & 1.88 & & 3 & 1 \\
\hline \multirow{2}{*}{ S15 } & 0.4 & 0.3 & & & 1.27 & 0.0 & 0.0 & 0.3 & 0.4 & & & 1.20 & 0.0 & 0.0 \\
\hline & 4 & 4 & 0.13 & 1.68 & & 5 & 1 & 9 & 7 & 0.16 & 1.60 & & 3 & 0 \\
\hline \multirow{2}{*}{ S16 } & 0.1 & 0.3 & & & 1.43 & 0.6 & 0.0 & 0.1 & 0.4 & & & 1.23 & 0.1 & 0.0 \\
\hline & 7 & 9 & 0.21 & 2.47 & & 9 & 8 & 1 & 8 & 0.25 & 2.20 & & 3 & 1 \\
\hline \multirow{2}{*}{ S17 } & 0.4 & 0.4 & & & 1.33 & 0.0 & 0.0 & 0.5 & 0.4 & & & 1.40 & 0.0 & 0.0 \\
\hline & 3 & 0 & 0.16 & 1.85 & & 6 & 2 & 7 & 3 & 0.16 & 1.63 & & 5 & 1 \\
\hline \multirow{2}{*}{ S18 } & 0.2 & 0.5 & & & 1.67 & 0.4 & 0.0 & 0.0 & 0.4 & & & 1.27 & 0.4 & 0.0 \\
\hline & 6 & 4 & 0.15 & 2.33 & & 8 & 7 & 6 & 5 & 0.24 & 2.17 & & 0 & 1 \\
\hline \multirow{2}{*}{ S19 } & 0.4 & 0.3 & & & 1.47 & 0.0 & 0.0 & 0.5 & 0.4 & & & 1.23 & 0.0 & 0.0 \\
\hline & 2 & 8 & 0.12 & 1.58 & & 7 & 2 & 8 & 6 & 0.14 & 1.60 & & 7 & 1 \\
\hline S20 & 0.2 & 0.6 & & & 1.50 & 0.6 & 0.0 & 0.0 & 0.4 & & & 1.20 & 0.2 & 0.0 \\
\hline$S \angle 0$ & 6 & 0 & 0.19 & 2.33 & & 5 & 6 & 3 & 5 & 0.25 & 2.13 & & 6 & 2 \\
\hline
\end{tabular}

Table 3 Pi index for water quality investigation of 20 sampling sites in spring, 2012

\begin{tabular}{|c|c|c|c|c|c|c|c|c|c|c|c|c|c|c|}
\hline \multicolumn{8}{|c|}{ Major tides } & \multicolumn{7}{|c|}{ Minor tides } \\
\hline Site & $\mathrm{pH}$ & DO & $\mathrm{COD}_{\mathrm{Mn}}$ & DIN & $\mathrm{PO}_{4}{ }^{3-}-\mathrm{P}$ & $\mathrm{PH}$ & Sul. & $\mathrm{pH}$ & DO & $\mathrm{COD}_{\mathrm{Mn}}$ & DIN & $\mathrm{PO}_{4}{ }^{3-}-\mathrm{P}$ & $\mathrm{PH}$ & Sul. \\
\hline \multirow{2}{*}{ S1 } & 0.3 & 0.4 & & & & 0.5 & 0.0 & 0.3 & 0.2 & & & & 0.3 & 0.0 \\
\hline & 6 & 1 & 0.56 & 1.09 & 0.25 & 2 & 1 & 0 & 9 & 0.29 & 1.46 & 0.57 & 6 & 1 \\
\hline \multirow{2}{*}{ S2 } & 0.2 & 0.2 & & & & 0.4 & 0.0 & 0.3 & 0.3 & & & & 0.3 & 0.0 \\
\hline & 5 & 0 & 0.56 & 1.09 & 0.33 & 7 & 1 & 1 & 0 & 0.31 & 1.48 & 0.47 & 9 & 1 \\
\hline \multirow{2}{*}{ S3 } & 0.1 & 0.1 & & & & 0.6 & 0.0 & 0.3 & 0.2 & & & & 0.4 & 0.0 \\
\hline & 6 & 5 & 0.51 & 1.01 & 0.22 & 6 & 1 & 1 & 7 & 0.30 & 1.63 & 0.52 & 7 & 1 \\
\hline \multirow{2}{*}{ S4 } & 0.4 & 0.4 & & & & 0.6 & 0.0 & 0.0 & 0.2 & & & & 0.4 & 0.0 \\
\hline & 3 & 8 & 0.63 & 1.09 & 0.13 & 4 & 2 & 9 & 2 & 0.43 & 1.88 & 0.70 & 1 & 1 \\
\hline \multirow{2}{*}{ S5 } & 0.5 & 0.3 & & & & 0.0 & 0.0 & 0.2 & 0.1 & & & & 0.0 & 0.0 \\
\hline & 1 & 3 & 0.40 & 0.85 & 0.30 & 8 & 0 & 8 & 3 & 0.32 & 1.32 & 0.61 & 8 & 0 \\
\hline S6 & 0.3 & 0.2 & 0.59 & 1.12 & 0.21 & 0.4 & 0.0 & 0.2 & 0.3 & 0.58 & 1.75 & 0.47 & 0.3 & 0.0 \\
\hline
\end{tabular}




\begin{tabular}{|c|c|c|c|c|c|c|c|c|c|c|c|c|c|c|}
\hline & 7 & 5 & & & & 5 & 1 & 1 & 0 & & & & 8 & 0 \\
\hline \multirow{2}{*}{ S7 } & 0.1 & 0.1 & & & & 0.4 & 0.0 & 0.2 & 0.3 & & & & 0.4 & 0.0 \\
\hline & 2 & 0 & 0.42 & 1.17 & 0.18 & 4 & 1 & 7 & 5 & 0.33 & 1.74 & 1.32 & 0 & 1 \\
\hline \multirow{2}{*}{ S8 } & 0.3 & 0.0 & & & & 0.0 & 0.0 & 0.2 & 0.3 & & & & 0.0 & 0.0 \\
\hline & 9 & 9 & 0.25 & 0.78 & 0.31 & 8 & 1 & 4 & 4 & 0.24 & 0.86 & 0.44 & 5 & 0 \\
\hline \multirow{2}{*}{ S9 } & 0.4 & 0.1 & & & & 0.0 & 0.0 & 0.2 & 0.3 & & & & 0.0 & 0.0 \\
\hline & 1 & 7 & 0.28 & 0.82 & 0.30 & 8 & 1 & 1 & 5 & 0.24 & 0.93 & 0.51 & 6 & 0 \\
\hline \multirow{2}{*}{ S10 } & 0.0 & 0.0 & & & & 0.4 & 0.0 & 0.3 & 0.3 & & & & 0.3 & 0.0 \\
\hline & 5 & 2 & 0.49 & 1.29 & 0.22 & 7 & 0 & 8 & 2 & 0.33 & 1.41 & 0.56 & 1 & 1 \\
\hline \multirow{2}{*}{ S11 } & 0.3 & 0.1 & & & & 0.0 & 0.0 & 0.2 & 0.3 & & & & 0.0 & 0.0 \\
\hline & 8 & 5 & 0.19 & 0.85 & 0.23 & 6 & 1 & 8 & 7 & 0.30 & 0.90 & 0.48 & 5 & 0 \\
\hline \multirow{2}{*}{ S12 } & 0.3 & 0.1 & & & & 0.0 & 0.0 & 0.2 & 0.2 & & & & 0.0 & 0.0 \\
\hline & 7 & 8 & 0.18 & 0.78 & 0.23 & 6 & 1 & 7 & 4 & 0.22 & 1.01 & 0.62 & 5 & 0 \\
\hline \multirow{2}{*}{ S13 } & 0.0 & 0.0 & & & & 0.4 & 0.0 & 0.4 & 0.3 & & & & 0.3 & 0.0 \\
\hline & 3 & 1 & 0.86 & 1.05 & 0.23 & 5 & 0 & 6 & 0 & 0.32 & 1.46 & 0.40 & 3 & 1 \\
\hline \multirow{2}{*}{ S14 } & 0.4 & 0.0 & & & & 0.0 & 0.0 & 0.3 & 0.3 & & & & 0.0 & 0.0 \\
\hline & 0 & 3 & 0.23 & 0.82 & 0.25 & 7 & 0 & 1 & 1 & 0.20 & 0.83 & 0.50 & 6 & 0 \\
\hline \multirow{2}{*}{ S15 } & 0.3 & 0.1 & & & & 0.0 & 0.0 & 0.2 & 0.3 & & & & 0.0 & 0.0 \\
\hline & 7 & 8 & 0.20 & 0.86 & 0.34 & 7 & 1 & 9 & 4 & 0.20 & 0.91 & 0.53 & 7 & 0 \\
\hline \multirow{2}{*}{ S16 } & 0.1 & 0.0 & & & & 0.5 & 0.0 & 0.5 & 0.3 & & & & 0.4 & 0.0 \\
\hline & 0 & 9 & 0.82 & 1.11 & 0.22 & 8 & 0 & 7 & 5 & 0.28 & 1.27 & 0.56 & 6 & 1 \\
\hline \multirow{2}{*}{ S17 } & 0.3 & 0.0 & & & & 0.0 & 0.0 & 0.3 & 0.3 & & & & 0.0 & 0.0 \\
\hline & 3 & 4 & 0.30 & 0.88 & 0.22 & 6 & 0 & 3 & 3 & 0.18 & 1.00 & 0.50 & 6 & 0 \\
\hline \multirow{2}{*}{ S18 } & 0.2 & 0.4 & & & & 0.4 & 0.0 & 0.6 & 0.3 & & & & 0.4 & 0.0 \\
\hline & 2 & 2 & 0.54 & 1.02 & 0.33 & 4 & 0 & 5 & 9 & 0.23 & 1.18 & 0.44 & 3 & 1 \\
\hline \multirow{2}{*}{ S19 } & 0.4 & 0.0 & & & & 0.0 & 0.0 & 0.3 & 0.3 & & & & 0.0 & 0.0 \\
\hline & 2 & 9 & 0.28 & 0.82 & 0.26 & 7 & 0 & 2 & 1 & 0.19 & 0.94 & 0.47 & 7 & 0 \\
\hline \multirow{2}{*}{ S20 } & 0.1 & 0.2 & & & & 0.4 & 0.0 & 0.7 & 0.4 & & & & 0.3 & 0.0 \\
\hline & 2 & 7 & 0.56 & 1.15 & 0.42 & 4 & 1 & 2 & 1 & 0.28 & 1.32 & 0.67 & 6 & 1 \\
\hline
\end{tabular}

The measured values of inorganic nitrogen in the two voyages in spring were $0.30 \mathrm{mg} \cdot \mathrm{L}^{-1}-0.57 \mathrm{mg} \bullet$ $\mathrm{L}^{-1}$, and Pi values were 0.78-1.88. The concentrations of inorganic nitrogen in 11 sites, S1, S2, S3, S4, S6, S7, S10, S13, S16, S18 and S20 during the major tide all exceeded the corresponding quality standards. The concentrations at other sites satisfied the quality standards. During minor tide, the concentrations of inorganic nitrogen at 14 sites exceeded the quality standards. They were S1, S2, S3, S4, S5, S6, S7, S10, S12, S13, S16, S17, S18 and S20. For other sites, the concentrations met the quality standards. The measured values of inorganic nitrogen in two voyages in autumn were $0.58 \mathrm{mg} \cdot$ $\mathrm{L}^{-1}-0.84 \mathrm{mg} \cdot \mathrm{L}^{-1}$, the average $0.69 \mathrm{mg} \cdot \mathrm{L}^{-1}$, and $\mathrm{Pi}$ value $1.58-2.63$. They all exceeded the corresponding quality standards, belonging to inferior class IV. The measured values of active phosphate in the two voyages in spring were $0.01 \mathrm{mg} \cdot \mathrm{L}^{-1}-0.04 \mathrm{mg} \cdot \mathrm{L}^{-1}$, and Pi value was $0.13-1.32$. The concentration at site S7 during minor tide exceeded the quality standard, and other sites met the standard. The measured values of active phosphate in the two voyages in the autumn were $0.032 \mathrm{mg} \cdot$ $\mathrm{L}^{-1}-0.047 \mathrm{mg} \cdot \mathrm{L}^{-1}$, the average $0.04 \mathrm{mg} \cdot \mathrm{L}^{-1}$ and $\mathrm{Pi}$ value $1.33-1.67$. They all exceeded the corresponding quality standard for sea water.

The measured values of petroleum hydrocarbons in the two voyages in spring were $14.7 \mu \mathrm{g} \bullet$ $\mathrm{L}^{-1}-32.9 \mu \mathrm{g} \cdot \mathrm{L}^{-1}$, and Pi value was $0.05-0.66$. They all satisfied the corresponding quality standards. The measured values in the two voyages in autumn were $6.6 \mu \mathrm{g} \bullet \mathrm{L}^{-1}-34.3 \mu \mathrm{g} \bullet \mathrm{L}^{-1}$, the average 18.1 $\mu \mathrm{g} \cdot \mathrm{L}^{-1}$, and Pi value $0.05-0.69$. They all satisfied the corresponding quality standards for sea water. The measured values of volatile phenols in the two voyages in spring were smaller than $2.2 \mu \mathrm{g} \cdot \mathrm{L}^{-1}$, and $\mathrm{Pi}$ values were smaller than 0.44 . They all satisfied the corresponding quality standards for sea water and also the class I quality standard. No volatile phenols were detected in autumn. The measured values of sulfides in four voyages were $0.20 \mu \mathrm{g} \bullet \mathrm{L}^{-1}-3.95 \mu \mathrm{g} \bullet \mathrm{L}^{-1}$, and Pi value was 0.00-0.07. They all satisfied the corresponding quality standards for sea water and also the class I quality standards. 
For heavy metal indicators from Fig.2, the measured values of $\mathrm{Cu}$ in the four voyages were 0.38 $\mu \mathrm{g} \bullet \mathrm{L}^{-1}-0.83 \mu \mathrm{g} \bullet \mathrm{L}^{-1}$, and Pi value was $0.01-0.08$. They satisfied the corresponding quality standards for sea water and also class I quality standard. The measured values of PS were $0.004 \mu \mathrm{g} \bullet$ $\mathrm{L}^{-1}-0.220 \mu \mathrm{g} \bullet \mathrm{L}^{-1}$, and Pi value was $0.00-0.04$. They satisfied the corresponding quality standards for sea water and also the class I quality standard. The measured values of $\mathrm{Zn}$ were $0.194 \mu \mathrm{g} \bullet \mathrm{L}^{-1}-1.393$ $\mu \mathrm{g} \cdot \mathrm{L}^{-1}$, and Pi values were $0.00-0.01$. They satisfied the corresponding quality standards for sea water and also the class I quality standard. The measured value of Cd were $0.02 \mu \mathrm{g} \bullet \mathrm{L}^{-1}-0.04 \mu \mathrm{g} \cdot \mathrm{L}^{-1}$, and $\mathrm{Pi}$ values were $0.00-0.01$. They satisfied the corresponding quality standards for sea water and also class I quality standard. The measured values of Cr were $0.05 \mu \mathrm{g} \bullet \mathrm{L}^{-1}-0.31 \mu \mathrm{g} \bullet \mathrm{L}^{-1}$, and Pi values were about 0.00 . They satisfied the corresponding quality standards for sea water and also the class I quality standard. The measured values of $\mathrm{Hg}$ were $0.01 \mu \mathrm{g} \bullet \mathrm{L}^{-1}-0.09 \mu \mathrm{g} \bullet \mathrm{L}^{-1}$, and Pi value were 0.06-0.17. They satisfied the corresponding quality standards for sea water. Except site S15 during major tide in autumn, all other sites met the class I quality standard for sea water. The measured values of As were $0.48 \mu \mathrm{g} \bullet \mathrm{L}^{-1}-2.60 \mu \mathrm{g} \bullet \mathrm{L}^{-1}$, and Pi values were $0.01-0.10$. They satisfied the corresponding quality standards for sea water and also class I quality standard.
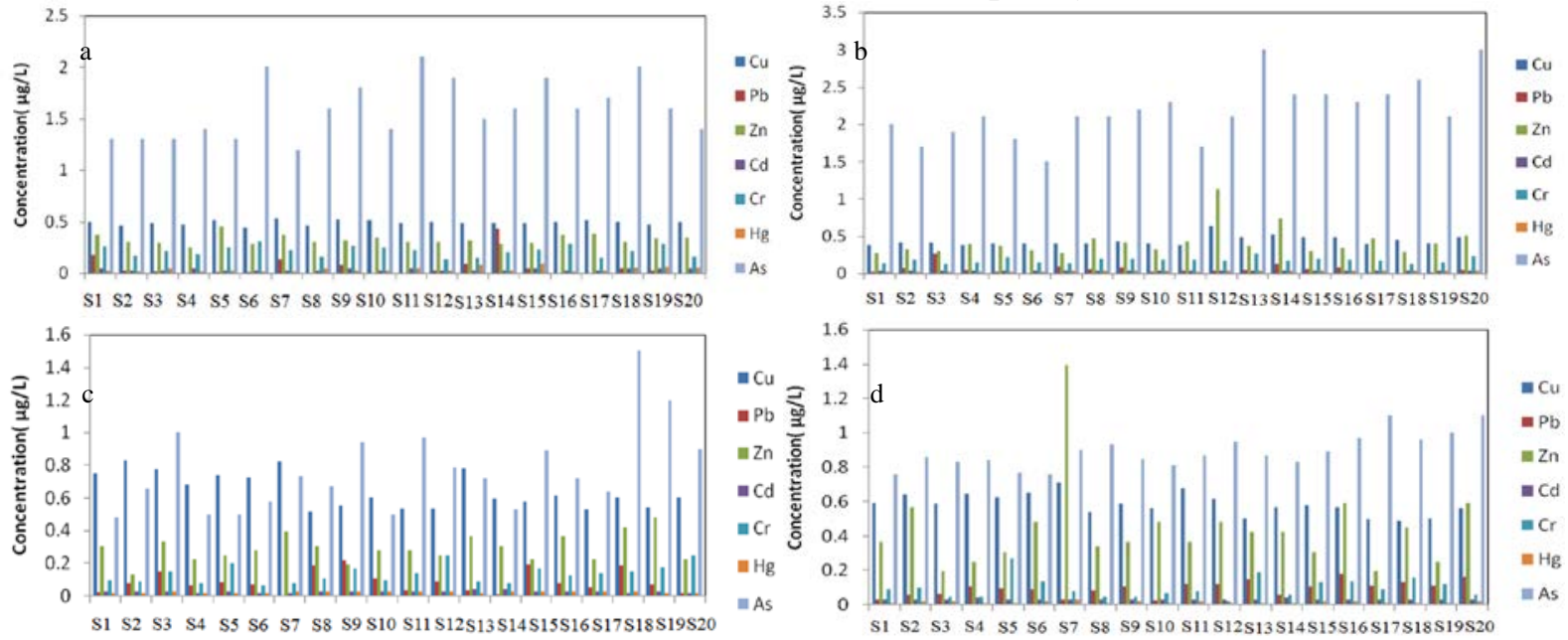

(a) Nov 22, 2010, (b) Nov 11, 2010, (c) Apr 23, 2012, (d)Apr 28, 2012

(b) Fig.2 Heavy metal concentrations in sea water.

For heavy metal indicators from Fig.2, the measured values of $\mathrm{Cu}$ in the four voyages were 0.38 $\mu \mathrm{g} \bullet \mathrm{L}^{-1}-0.83 \mu \mathrm{g} \bullet \mathrm{L}^{-1}$, and $\mathrm{Pi}$ value was $0.01-0.08$. They satisfied the corresponding quality standards for sea water and also class I quality standard. The measured values of PS were $0.004 \mu \mathrm{g} \bullet$ $\mathrm{L}^{-1}-0.220 \mu \mathrm{g} \bullet \mathrm{L}^{-1}$, and Pi value was $0.00-0.04$. They satisfied the corresponding quality standards for sea water and also the class I quality standard. The measured values of $\mathrm{Zn}$ were $0.194 \mu \mathrm{g} \bullet \mathrm{L}^{-1}-1.393$ $\mu \mathrm{g} \bullet \mathrm{L}^{-1}$, and Pi values were 0.00-0.01. They satisfied the corresponding quality standards for sea water and also the class I quality standard. The measured value of Cd were $0.02 \mu \mathrm{g} \bullet \mathrm{L}^{-1}-0.04 \mu \mathrm{g} \bullet \mathrm{L}^{-1}$, and Pi values were 0.00-0.01. They satisfied the corresponding quality standards for sea water and also class I quality standard. The measured values of Cr were $0.05 \mu \mathrm{g} \bullet \mathrm{L}^{-1}-0.31 \mu \mathrm{g} \bullet \mathrm{L}^{-1}$, and Pi values were about 0.00 . They satisfied the corresponding quality standards for sea water and also the class I quality standard. The measured values of $\mathrm{Hg}$ were $0.01 \mu \mathrm{g} \bullet \mathrm{L}^{-1}-0.09 \mu \mathrm{g} \bullet \mathrm{L}^{-1}$, and Pi value were 0.06-0.17. They satisfied the corresponding quality standards for sea water. Except site S15 during major tide in autumn, all other sites met the class I quality standard for sea water. The measured values of As were $0.48 \mu \mathrm{g} \bullet \mathrm{L}^{-1}-2.60 \mu \mathrm{g} \bullet \mathrm{L}^{-1}$, and $\mathrm{Pi}$ values were $0.01-0.10$. They satisfied the corresponding quality standards for sea water and also class I quality standard.

The statistics of surveys in four voyages in spring and autumn in this sea area indicates obvious eutrophication of water. The concentrations of inorganic nitrogen at 11 sites, S1, S2, S3, S4, S6, S7, S10, S13, S16, S18 and S20 exceeded the corresponding quality standards for sea water during the major tide in spring. The concentrations of inorganic nitrogen at 14 sites, S1, S2, S3, S4, S5, S6, S7, S10, S12, S13, S16, S17, S18 and S20, exceeded the corresponding quality standards during the minor tide. At site S7, the concentration of active phosphate during minor period in spring exceeded 
the corresponding quality standards for sea water. The eutrophication of sea water in the two voyages in autumn was more severe than that in spring. The concentrations of inorganic nitrogen (Pi: 1.58-2.63) and active phosphate (Pi: 1.33-1.67) all exceeded the corresponding quality standards for sea water. All other indicators measured in the four voyages met the corresponding quality standards for sea water. Generally speaking, the background values of heavy metals in the sea area were low. Only Hg concentration exceeded the standard at site S15. The water quality was basically good except eutrophication. This might be due to the influence of long shore currents of Fujian and Zhejiang in this sea area during the survey period, when the levels of nutritive salts reached the maximum of the year.

\section{Conclusions}

The study area proved to have a low level of heavy metals. Hg concentrations only exceeded the standard at individual sites. However, eutrophication in autumn was observed more serious than in spring, which is mainly caused by the excessive inorganic nitrogen and active phosphate, all exceeding the corresponding quality standards for sea water in autumn.

\section{Acknowledgements}

I could like to personal thank the help from corresponding author Liping Jiao and gratefully acknowledge the Grants from the Scientific Research Foundation of Third Institute of Oceanography, SOA (2011016), Public science and technology research funds projects of ocean (20130523-1) and Zhejiang Provincial Natural Science Foundation (LQ13D030001). The authors would like to acknowledge anonymous reviewers for helpful comments on the manuscript.

\section{References}

[1] Adams W J, Kimerle R A, Barnett J W. Sediment quality and aquatic life assessment[J]. Environmental Science \&Technology, 1992, 26(10), 1864-1875.

[2] Chen J S, Cheng J. A fuzzy cluster analysis of water quality of major gulfs in the coastal zone of Fujian Province [J]. Journal of Fujian Teachers University (Natural Science), 2001,17(4):101-120. (in chinese)

[3] Feng H, Jiang H, Gao W, et al. Metal contamination in sediments of the western Bohai bay and adjacent estuaries, China[J]. Journal of Environmental Management, 2011, 92(4), 1185-1197

[4] Gao S, Luo T C, Zhang S R, et al. Chemical composition of the continental crust as revealed by studies in East China[J]. Geochimica et Cosmochimica Acta, 1998, 62(11), 1959-1975.

[5] Gao X, Chen C T . Heavy metal pollution status in surface sediments of the coastal Bohai bay[J]. Water Research, 2012, 46(6), 1901-1911.

[6] Gao X, Li P. Concentration and fractionation of trace metals in surface sediments of intertidal Bohai bay, China[J]. Marine Pollution Bulletin, 2012, 64(8), 1529-1536.

[7] Hakanson L. An ecological risk index for aquatic pollution control: a sedimentological approach[J]. Water Res, 1980,14(8): 975-1001.

[8] Hu S Q, Li G G, Li J, et al. Spatial distribution and ecotoxicological risk assessment of heavy metals in surface sediments of the southern Sohai bay, China [J]. Environ. Sci. Pollut. Res., 2013, 20: 4099-4110.

[9] Liu S, Shi X, Liu Y, et al. Concentration distribution and assessment of heavy metals in sediments of mud area from inner continental shelf of the East China Sea[J]. Environmental Earth Sciences, 2011, 64(2), 567-579 
[10]LuoD.L.RuanJ S, Xu C Y, et al. Concentration of the heavy metals and organic matter in surface sediments from the main shellfish culture areas of Fujian and their correlativity [J]. Marine Environmental Science, 2004,23(1): 33-36.(in chinese)

[11]Pan K, Wang W X. Trace metal contamination in estuarine and coastal environments in China[J]. The Science of the Total Environment, 2012, 421-422, 3-16.

[12]Pekey H. Heavy metal pollution assessment in sediments of the Izmit bay, Turkey[J]. Environmental Monitoring and Assessment, 2006, 123(1-3), 219-231

[13] Sundaray S K, Nayak S S, Lin S, et al. Geochemical speciation and risk assessment of heavy metals in the river estuarine sediments--a case study: Mahanadi Basin, India[J]. Journal of Hazardous Materials, 2011, 186(2-3), 1837-1846.

[14] Tessier E, Garnier C, Mullot J U, et al. Study of the spatial and historical distribution of sediment inorganic contamination in the Toulon bay (France) [J]. Marine Pollution Bulletin, 2011, 62(10), 2075-2086.

[15] Varol M. Assessment of heavy metal contamination in sediments of the Tigris River (Turkey) using pollution indices and multivariate statistical techniques[J]. Journal of Hazardous Materials, 2011, 195, 355-364.

[16]Waing X, Li W Q, Zhang F. Assessment on present status and quality of sediment in Fujian shore bay[J]. Acta Oceanologica Sinica , 2002, 24(4): 127-131.(in chinese)

[17]Waing $X$. Distribution features of oil in water and sediment in Fujian shore[J]. Journal of Xiamen University (Natural Science), 2000,39(3):369-374. (in chinese)

[18] Wang C, Sun Q, Jiang S, et al. Evaluation of pollution source of the bays in Fujian Province [J]. Procedia Environmental Sciences, 2011, 10: 685-690.

[19]Wu Z, He M, Lin C. Environmental impacts of heavy metals (Co, Cu, PS, Zn) in surficial sediments of estuary in Daliao River and Yingkou bay (northeast China): concentration level and chemical fraction[J]. Environmental Earth Sciences, 2012, 66(8), 2417-2430.

[20] Yang G D, Zheng J P, Chen L, et al. Speciation analysis and characterization of arsenic in lavers collected from coastal waters of Fujian, south-eastern China [J]. Food Chemistry, 2012, 132, 1480-1485.

[21]Zhang Y B, Hue Y L, Liu X Y, et al. Environmental impact factors and mercury speciation in the sediment along Fujian and eastern Guangdong coasts [J] Acta. Oceanol. Sin., 2013, 32 (2): 76-80. 